\title{
Different enriched environments for Eurasian lynx in the Barnaul Zoo
}

\author{
T. V. Antonenko*1, 0. M. Ulitina ${ }^{2}$, S. V. Pysarev $^{3}$, A. V. Matsyura ${ }^{1}$ \\ ${ }^{1}$ Altay State University, Russia \\ ${ }^{2}$ Altay State Medicine University, Russia \\ ${ }^{3}$ Barnaul Zoo, Russia \\ Corresponding Author E-mail: tv bio@mail.ru
}

Received 16.10.2019 Accepted 14.12.2019

\begin{abstract}
Our primary interest is in welfare of Eurasian lynx ( Lynx lynx) in the Barnaul Zoo. As discussed below, behavioural researches can reveal much about the welfare of captive wild animals. Eurasian lynx behaviour is studied and time budget is calculated for male and female. The Schorygin' similarity coefficient of behaviour is determined $(87.2 \%)$. The male lynx demonstrated low degree of stereotypic behaviour $-5.9 \%$, the female lynx-3.8\%. We analyzed the differences in their behaviour before and after environmental enrichment. Olfactory environmental enrichment exhibits a decrease of male stereotypic behaviour on $24.3 \%$ and of female on $18.8 \%$. Feeding environmental enrichment reduces male stereotypic behaviour on $15.9 \%$, female on $20.3 \%$ (with a rat trunk); the male lynx pacing is diminished on $0.9 \%$ and female stereotypic behaviour on $1.4 \%$ in experiments with meat under fresh-cut grass. Based on our findings, we recommend that lynxes should be housed by mating pair (male with female), with appropriate hiding locations and with the varied feeding, change decorations for captive lynx, carry out tests by olfactory environmental enrichment (with pony droppings and with valerian) and feeding environmental enrichment. It could be concluded that animal welfare depends on keepers' goodwill relation with captive lynx.
\end{abstract}

Key words: Animal welfare; Barnaul Zoo; Captive lynx; Environmental enrichment; Eurasian lynx; Lynx lynx.

\section{Introduction}

The welfare and behaviour of captive wild animals can be heavily influenced by their zoo habitats and husbandry systems. Extremely essential is the need to create, provide and optimize captive environments (Clubb, Mason, 2007; Tribe et al., 2014; Antonenko et al., 2017). Captive environments often fail to resemble the wild environment in limited space, unchanging habit, lack of stimulus and contingency. Common animal welfare problems which occur with captive animals include low behavioural diversity, abnormal behaviour and excessive inactivity (Mason et al., 2014; Yu et al., 2009).

Felids are presented in zoos all over the world. They always get the attention of visitors. Environmental enrichment is one of the factors of an animal welfare that seeks to enhance the quality of captive felids care by identifying and providing the environmental stimuli necessary for optimal psychological and physiological well-being. There are eight felids species in Barnaul zoo. The paper studies only one species-Eurasian lynx Lynx lynx (L. 1758). Eurasian lynx inhabits the entire territory of Russia. However, its population is small and is 27-30 thousand animals in Russia and 451 individuals are accounted for the period 2013/2014 years on the Altai Territory. A low abundance depends on exogenous (lynx-an object of hunting) and endogenous factors (early sibling aggression, which resulted in up to 10\% dying kittens) (Naidenko, 1997; Antonevich, Erofeeva, Naidenko, 2012). Thus, study of the behaviour of the Eurasian lynx and their conditions in zoos and specialized nurseries has a practical and theoretical significance.

The chief purpose of the investigation is to establish special aspects of the behaviour of the Eurasian lynx Lynx lynx and optimize their conditions in the Barnaul Zoo. The secondary aim is to estimate the time budget for male and female. The third object of the experiments is to compare the conditions of captivity $L y n x$ lynx with principals of animal welfare. The final purpose is to make environmental enrichment and to reduce pacing of felids.

\section{Materials and Methods}

The studies were conducted at the Barnaul Zoo "Forest Fairy Tale" from 18 June to 28 July 2012 and from June 3 to July $29,2013$. Period of monitoring of male and female was 120 hours. Cats behaviour are studied by continuous real-time measurement and "Ad Libitum" (Altmann, 1974; Altmann, 1984; Martin, Bateson, 1993; Lehner, 1996). The Schorygin' similarity coefficient of behaviour is determined (Popov, Il'chenko, 2008). The Schorygin' similarity coefficient is used to compare the time budget for animals with identical ethograms. The data on the occurrence or the place in the time budget patterns of behaviour should be presented in the percent or unit fraction (total incidence of all elements of ethograms or all of the time budget - 100\% or 1.0 ). A number of occurrence of the minimum values for each form of activity of the two animals is composed and the terms of this series are summarized to calculate Schorygin' similarity coefficient. The resulting sum of the minimum values is the Schorygin' similarity coefficient. Olfactory environmental enrichment has been investigated by pony dung and with a roots of Valeriana officinalis inside bags. Feeding environmental enrichment was carried out through the use of rat carcasses and by dint of meat under freshly grass. Rats were mortified by cervical dislocation. Carcasses of rats were suspended from the ceiling of the cage with a wire. Photographic work and videorecording were carried Canon PowerShot SX120 IS. 


\section{Results and Discussion}

In order to assess the well-being of the animal it is important to quantitate the time' budget and to analyze the causes of such pathological behaviours such as movement stereotypes, abnormal immobility, long-term stay in the shelter and others (Table 1).

Table 1. A time budget of male and female Lynx lynx.

\section{Activity pattern}

observation time,
$\%$

Sleep (lies with opened eyes)

Rest (lies with closed eyes)

Watchful rest (lies, moves with ears)

Freezing behaviour (abrupt cessation of motion and strained pose)

Motion into the cage (locomotion)

Stereotyped behaviour (pacing)

Play behaviour

Feeding behaviour

Grooming

Exploratory behaviour

Hunting behaviour

Orientation behaviourActivir

The animal is in the shelter

Static behaviour

Marking behaviour

\section{Male, the proportion of total $\%$}

4.5

2.5

15.7

5.9

3

2.8

3.3

3.4

3.6

3.1

-

2.5

3.2

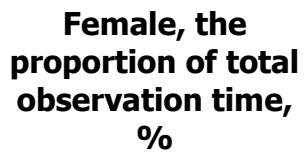

Female, the proportion of total observation time, $\%$

Cats are specialized predators eating high-calorie food, so most of the time of day they spend in an inactive state (sleep, doze, lie). Sleep predominates in behaviour of lynxes male and female ( $25.8 \%$ and $32.9 \%$, respectively), and the leisure (about $21 \%)$ like in most cats. The low proportion of stereotypical behaviour (male-5.9\% and the female-3.8\%) suggests that animals in general, are in favorable conditions. Keeping animals in pairs also has a beneficial effect. There was no male presence in the shelter (house at a height of about $1.5 \mathrm{~m}$ ) during the observation period. This pair of animals has a high coefficient of Shorygin-87.2\%, which indicates the high similarity of the behaviour of these Eurasian lynxes and their harmonious existence in a limited area.

According to the principle of the animals welfare in captivity we have analyzed the conditions of Eurasian lynx' keeping in the Barnaul Zoo. Cats are kept together for several years in a cage with natural vegetation. Keeping predators in a pair leads to increase of their exploratory and motor activity and reduce pathological behaviour. Furthermore, it is also successful for reproduction. During the three years of living in Barnaul Zoo lynxes have brought posterity.

Lattice is used as the material for fencing. These lattices or reticulated types of fences can cause increase of injury in animals and are not safe for visitors. However, was no accidents have been reported for all time of the lynxes keeping. Due to the location, the cage is viewed from one side only. It is also considered advantageous because animals can hide from visitors.

The complexity of the cage can be more important than its size. So, for lynxes there is installed a one storey house, situated at an altitude and house set on the ground (robust places to stay where lynxes feel in safety), there is also 3 stumps, 1 large stone, and 2 logs, located horizontally at the altitude. Static scenery in cages does not change, so that the animals can not vary their behaviour and usual movement patterns. Change of scenery occurs naturally due to vegetation in the cage. In the cage there are tree the trunks for scratching, which also helps to avoid problems arising from of ingrown claws. Cage equipment provides a simple and easy animals' movement from one part of the construction to another (Table 2).

Feeding is a very important moment in cats' keeping. During the week, cats receive a wide range of food (meat, chicken carcasses, eggs, fish and etc.). Every Monday at the zoo lynxes have a "hungry" day in order not to get obese.

Barnaul Zoo employs experienced keepers who can find contact and mutual understanding with animals. Keepers communicate with lynxes daily and create a special atmosphere, allowing the animals to partly compensate the negative captivity factors. Relationship with animals are developed since their arrival at the zoo. All the staff actions have calm character, for the animals not to feel stress and as a consequence of stress reaction - not to reveal aggression. The predators that appeared in the zoo at an early age know the zoo staff and feel them when they pass by. Good relations between animals and zoo staff facilitate daily routine procedures, such as cleaning, feeding, treatment etc. Keepers cleaned the animal cages two times per day. Drinking water sources are controlled from outside and can be replaced at any time. 
Table 2. Exposure enclosures Eurasian lynx.

\begin{tabular}{ccccccc}
\hline Animals & $\begin{array}{c}\text { Possibility of } \\
\text { privacy }\end{array}$ & $\begin{array}{c}\text { Social } \\
\text { companions }\end{array}$ & $\begin{array}{c}\text { Using } \\
\text { multiple } \\
\text { tiers }\end{array}$ & $\begin{array}{c}\text { Change of } \\
\text { scenery }\end{array}$ & $\begin{array}{c}\text { Wooden } \\
\text { structures }\end{array}$ & $\begin{array}{c}\text { Herbal } \\
\text { floor }\end{array}$ \\
$\begin{array}{c}\text { Male and } \\
\text { female }\end{array}$ & + & + & + & + & + & + \\
\hline
\end{tabular}

Stimulation of various forms of natural behaviour in animals requires not only ensuring their cages with adequate size and appropriate design. Animals' welfare requires further work on environmental enrichment. The olfactory methods with using of different scents can stimulate cats' exploratory activity. Thus, the excrement of ungulates (pony) in the propylene sack was proposed for lynxes for familiarization. Lynxes have spent on the experiment: male -15 minutes, the female -7 minutes. Here cats' actions were targeted and had elements of comfort, able territorial and hunting behaviour. The smell of large ungulates' excrements caused a strong reaction, because the herbivores in nature for them are potential prey (Table 3).

The second olfactory experiment was introduction of the valerian roots in plastic bags in the lynx's cage. Actinidin is known to have an active influence on cats. Its action is related to be fact that actinidin's smell is similar to the smell of the substance contained in the cats' urine. During the experiments, the predators demonstrated the elements of behaviour similar to the domestic felines. Initially the animals showed exploratory behaviour, after that licked, dragged the sack with valerians roots, rolled on the ground and chewed the sack. The time of the experiment for the lynx's male was for the 11 minutes, for the female cat -6 minutes (Table 3).

Table 3. Olfactory enrichment.

\section{Enrichment object}

Male, min.

15

Pony dung

Roots of Valeriana officinalis
6

The female of lynx was more conservative in her behaviour and spent less time on the experiment (Figure 1).

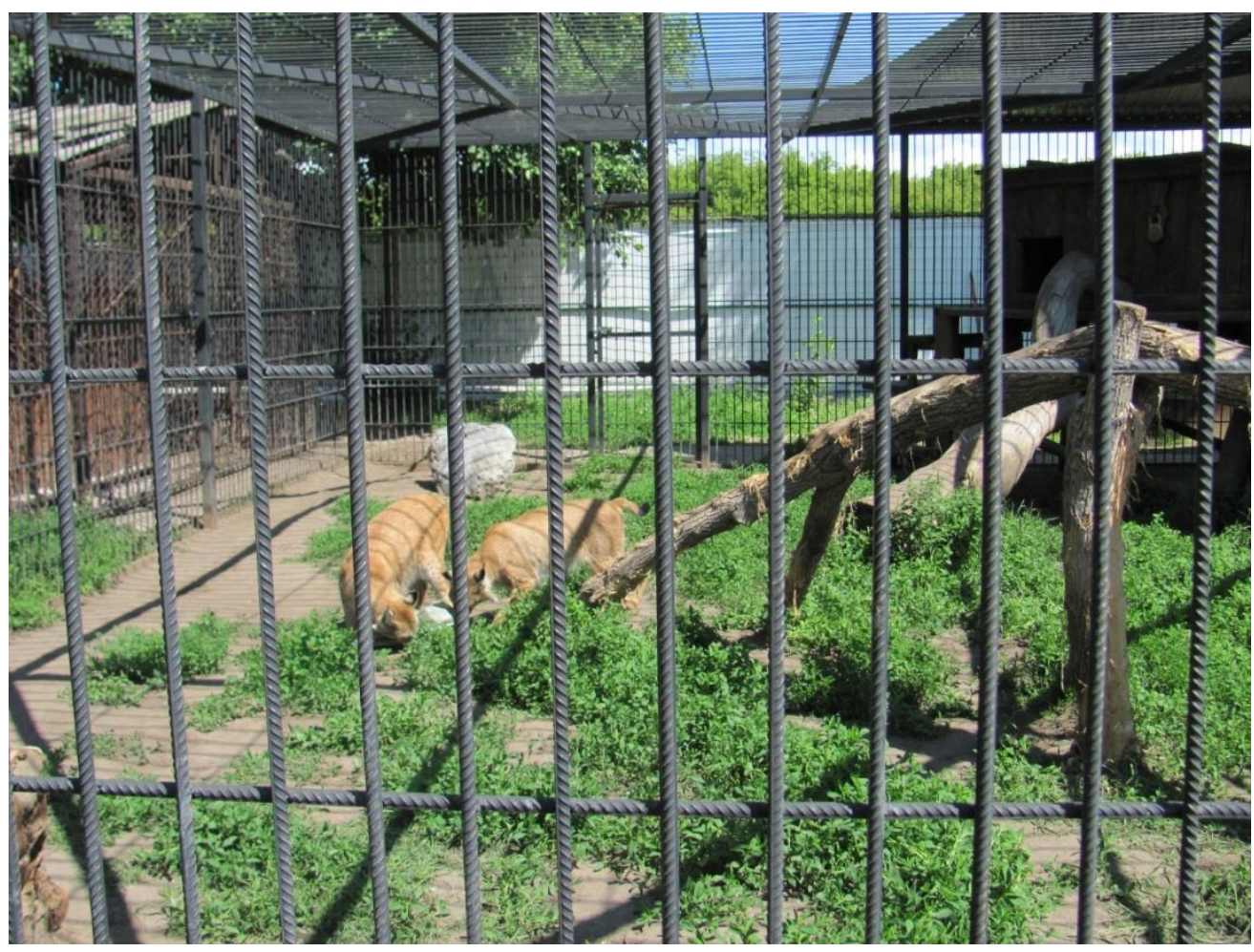

Figure 1. Olfactory enrichment with roots of Valeriana officinalis.

Thus, olfactory enrichment has attracted considerable interest from the Eurasian lynx, but it has limited time interval. Stereotyped behaviour decreased in males at $24.3 \%$, in female lynx by $18.8 \%$. Even short-term environmental enrichment reduces the proportion of pathological behaviour. Feeding enrichment with inanimate potential victims is also carried out in all the worlds' zoos. Conducting the experiment with the mortified rat hanging on the wire, identified the following types of behaviour: cognitive, exploratory, food, hunting and playing. Booty was hung up under the ceiling in the cage so that the animals could not get it directly with paws. Cats had to calculate the path to achieve and get it. Thus, we can speak not only about food behaviour, but also about cognitive part of environment enrichment. In these two experiments, male showed a more long-lasting interest than the female (Figure 2). 


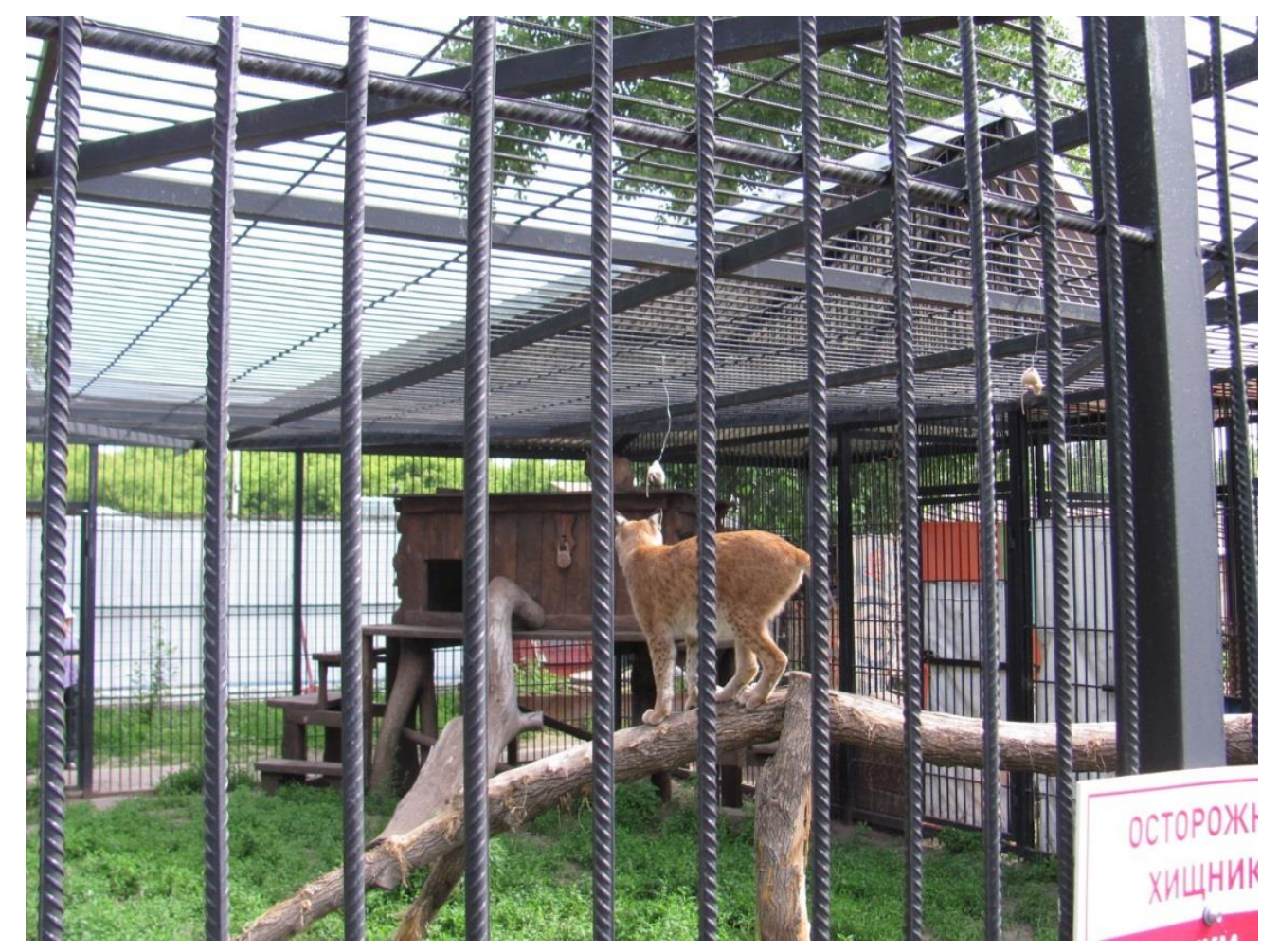

Figure 2. Feeding enrichment with rat carcass suspended from the ceiling of the cage with a wire.

In the experiment with fresh-cut grass, a bowl with meat covered with grass was put before predators. The time from the beginning of the food search to its detection was recorded. In this experiment, the animals demonstrated exploratory and feeding behaviour. During the experiment, it was observed that initially approached food male and female later. Lynxes quickly found the hidden food and ate it (Table 4).

Table 4. Feeding enrichment.

Enrichment object

Rat carcasses

Meat under freshly grass
Male (min)

17

1
Female (min)

14

1

Thus, in the course of food enrichment of the environment the reduction was made of share of pacing in experiments with rat carcass for male by $15.9 \%$ for females $-20.3 \%$; in experiments with meat under the grass by $0.9 \%$ and $1.4 \%$, respectively. On the whole, it is worth noting that the food enrichment increases the proportion of normal activity, increases exploratory and hunting behaviour reduces the proportion of stereotypies. In the behaviour of male and female lynx sleep $(25.8 \%$ and $32.9 \%$, respectively) and leisure $(20.6 \%)$ predominated. There was a low proportion of stereotypical behaviour (male $-5.9 \%$ and the female $-3.8 \%$ ).

\section{Conclusion}

Cages are constructed partially according to the principles of animal welfare (change of scenery with a help of landscaping, the presence of vertical and horizontal logs, shelters, the cage is viewed by visitors only from one side). It friendly attitude of keepers to cats was noted. There is a constant change of diet. Keeping the lynxes in pairs affects them favorably. Stereotypic behaviour after olfactory enrichment decreased in lynx's male by $24.3 \%$, the female $-18.8 \%$. Food environment enrichment reduced the share of stereotypes in the experiments with rat carcass for male by $15.9 \%$ for female on $20.3 \%$; experiments with covered with fresh grass meat by $0.9 \%$ and $1.4 \%$, respectively. The most optimal and successful experiments for environment enrichment with the Eurasian lynx are olfactory enrichment with excrement of ungulates and valerian roots and food enrichment with alive and mortified objects.

\section{References}

Altmann, J. (1974). Observational study of behavior, sampling methods. Behaviour, 49, 227-267.

Altmann, J. (1984). Observational sampling methods for insect behavioral ecology. Florida Entomol, 67, 50-56.

Antonenko, T.V., Panchuk, K.A., Medvedeva, Yu.E. (2017). The influence of olfactory enrichment on the welfare of large felines in captivity. Ukrainian Journal of Ecology, 7(4), 134-138, doi: 10.15421/2017_105

Antonevich, A.L., Erofeeva, M.N., Naidenko, S.V. (2012). Early sibling aggression of Eurasian lynx depends on the growth rate. Doklady Akademii Nauk, 447(3), 340-342.

Clubb, R., Mason, G.J. (2007) Natural behavioural biology as a risk factor in carnivore welfare: How analysing species differences could help zoos improve enclosures. Applied Animal Behaviour Science, 102(3-4), 303-328.

Lehner, P.N. (1996). Handbook of Ethological Methods, 2-nd ed. Cambridge University Press. Cambridge, UK. 
Mason, G., Burn, C. C., Dallaire, J. A., Kroshko, J., McDonald Kinkaid, H., Jeschke J. M. (2013). Plastic animals in cages: behavioural flexibility and responses to captivity. Animal Behaviour, 85(5), 1113-1126.

Martin, P., Bateson, P. (1993) Measuring Behaviour: An Introductory Guide, 2-nd ed. Cambridge University Press. Cambridge, UK. Naidenko, S.V. (1997). The social behaviour of lynx (Lynx lynx Linnaeus, 1758) and the features of its formation in ontogenesis. Thesis of Doctoral Dissertation. Moscow (In Russian).

Popov, S.V., Il'chenko, O.G. (2008) Guide to research in zoos: Methodological recommendations on ethological observations of mammals in zoos. Moscow: Moscow Zoo (In Russian).

Tribe, A., Clark, G., Galloway, T.K., Hansen, K., Phillips, C.J.C. (2014) Emotional states and enrichment in captive big cats. Recent advances in animal welfare science IV UFAW Animal Welfare Conference York Merchant Adventurers' Hall UK.

Yu, S., Jiang, Z., Zhu, H., Li, C., Zhang, E., Zhang, J., Harrison, C. (2009). Effects of odors on behaviors of captive Amur leopards Panthera pardus orientalis. Current Zoology, 55(1), 20-27.

\section{Citation:}

Antonenko, T.V., Ulitina, O.M., Pysarev, S.V., Matsyura, A.V. (2019). Different enriched environmens for Eurasian lynx in the Barnaul Zoo. Ukrainian Journal of Ecology, 9(4), 671-675.

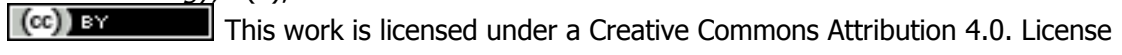

